\title{
PRECARIZAC̄̃̃O SOCIAL DO TRABALHO E RESISTÊNCIAS PARA A (RE) CONQUISTA DOS DIREITOS DOS TRABALHADORES NA FRANÇA ${ }^{1}$
}

\begin{abstract}
Annie Thebaud-Mony*
Este artigo apresenta, inicialmente, algumas grandes etapas históricas da conquista dos direitos de trabalhadores na Franç, sublinhando o que levou a um real reconhecimento oficial dos direitos em matéria de luta para a melhoria das condições de trabalho. No decorrer dos anos 1970, quando a "flexibilidade" se tornou a palavra de ordem da reestruturação das empresas, duas leis questionam a proibição da intermediação de mão de obra, instaurando um processo estrutural de precarização do trabalho e do emprego, que alterou não somente a segurança econômica dos assalariados como o conjunto dos direitos associados ao contrato de trabalho. Esse processo desmonta, em grande parte, o direito à saúde dos trabalhadores nos locais de trabalho, a exemplo dos cânceres profissionais, como revela pesquisa permanente realizada em uma região parisiense, junto a pacientes acometidos de câncer. Novas redes de resistência, no mais das vezes internacionais e constituídas numa base cidadã, organizam-se, entretanto, em torno dos desafios de saúde, tal como é tratado na conclusão.

PALAVRAS-CHAVE: precarização, cânceres profissionais, direitos, resistências, França.
\end{abstract}

\section{INTRODUÇÃO}

Na França, como em todos os países industrializados, a partir do fim dos anos 1970, a "flexibilidade" se tornou a palavra de ordem da reestruturação das empresas, uma virtude nova erigida pelo patronato e os poderes públicos como valor de referência da volta ao crescimento. Sob esse vocábulo abstrato se dissimulam os fenômenos materiais de transformações do trabalho: intensificação do trabalho, demissões, instalação de um desemprego estrutural, destruição dos coletivos de trabalho, erosão dos direitos ligados ao contrato de trabalho, em especial pelo recurso ao trabalho temporário e à terceirização. Podese acrescentar a tal lista a deslocalização das produções de risco para os países cujas condições

* Socióloga. Diretora de pesquisa no Instituto Nacional de Saude e Pesquisa Medica (INSERM).

Université Paris13. 74 rue Marcel Cachin. 93017 - BOBIGNY

- cedex, France. annie.thebaud-mony@wanadoo.fr

${ }^{1}$ Traduzido por Michel Colin. Revisão de Graça Druck. salariais são menos onerosas e as regulamentações sobre a saúde e o meio ambiente inexistentes. Como eu pude mostrar no âmbito de uma cooperação franco-brasileira (Thébaud-Mony, 1990), terceirizar ou deslocalizar os riscos, em vez de investir para controlá-los, são as duas facetas de uma mesma estratégia industrial. Entretanto, certas leis, contraditórias com essa exigência de flexibilidade, existem na França há mais de um século e meio e, em teoria, reconhecem aos trabalhadores direitos em matéria de segurança econômica, mas também de cidadania na empresa, em especial no que diz respeito à proteção à saúde.

O presente artigo apresenta, inicialmente, algumas grandes etapas históricas da conquista dos direitos de trabalhadores na França. A seguir, analisa a "desorganização" do trabalho, que se opera no decorrer dos últimos trinta anos, e suas consequências sobre a saúde dos trabalhadores, em especial no que concerne aos riscos mais graves. E, por fim, trata das resistências que se organizam nacional e internacionalmente diante dos desafios da saúde do trabalhador. 


\section{BREVE HISTÓRIA DA CONQUISTA DOS DIREITOS DE TRABALHADORES NA FRANÇA}

A primeira verdadeira conquista operária em matéria de direitos dos trabalhadores no capitalismo do século XIX é a lei de proibição da "marchandage de main d'œuvre", ${ }^{2}$ votada pelo parlamento francês em março de 1848. Essa lei proíbe a um empresário obter lucro "alugando" os serviços de seus próprios assalariados a outros empregadores. Essa lei é o fundamento do contrato de trabalho direto entre empregador e assalariado que, durante um século, será o modelo dominante do emprego na França (mesmo existindo exceções, em especial em relação aos imigrantes, frequentemente recrutados no quadro de contratos temporários ou sazonais).

Leis buscando a regulamentação de trabalho das crianças são encontradas de 1841 a 1926, como a lei de 7 de dezembro de 1926, que proíbe as crianças de realizarem trabalhos perigosos, insalubres, em que ficariam expostas a "emanações prejudiciais para sua saúde”. Antes, a lei sobre a salubridade das oficinas (1893) representou uma conquista maior para o direito à saúde dos trabalhadores nos locais de trabalho. Essa lei obriga o empregador a manter as oficinas limpas, livres de qualquer contaminação por gases, fumaças, poeiras suscetíveis de acometer a saúde dos operários. Em 1893, igualmente, a inspeção do trabalho é criada, para assegurar uma missão de "ordem públi-

${ }^{2}$ A “merchandage de main d'œuvre" corresponderia ao que se denomina, no Brasil, de intermediação de mão de obra (N.doT.) do, as negociações sociais após as quais essa lei foi adotada não fundaram um direito que privilegiasse a proteção dos operários contra os acidentes de trabalho. Esse direito à indenização em caso de acidente de trabalho se inscreveu em uma lógica de risco segurável. De acordo com os princípios do seguro, o paralelo pode ser feito entre esse "risco" profissional e o "risco" de "danos das águas". Em ambos os casos, o raciocínio é o mesmo. O segurador não se preocupa em conhecer a causa, mas tão somente verificar que o "acidente" depende do contrato e de suas regras entre segurador e "segurado". No caso de um acidente profissional, o segurado não é o trabalhador acidentado, mas o empregador, que receberá um aumento de sua cotização específica sobre os acidentes de trabalho, em função daqueles que ele declara e que são reconhecidos como indenizáveis no âmbito da lei.

Em 1919, nos dias que seguem à primeira guerra mundial, o direito ao reconhecimento das doenças profissionais se inscreve na mesma perspectiva. Os limites desse direito são aqueles de "quadros de doença profissional" estritamente regulamentados. No final da segunda guerra mundial, na França, um Conselho Nacional da Resistência elabora um programa prevendo reformas maiores, em especial no campo da proteção social (Cidadãos resistentes de ontem e de hoje, 2010). Em 1945, a seguridade social é criada. Fundada sobre o princípio de solidariedade, ela assume o conjunto dos riscos sociais (desemprego, doença, aposentadoria, acidente de trabalho e doença profissional).

A partir de 1945, no período do fordismo, o sindicalismo adquire, na França, uma força e uma legitimidade sem precedentes para a defesa dos direitos dos trabalhadores. No entanto, o princípio de divisão do trabalho e dos coletivos, fundamento da organização capitalista do trabalho, manifesta-se pela desigualdade dos direitos entre trabalhadores franceses e imigrantes, homens e mulheres, adultos e jovens. As reivindicações são essencialmente salariais, a insalubridade e a dureza das condições de trabalho nas minas, e fábri- 
cas são objeto de negociações para compensações monetárias. Nos anos 1960, um movimento de resistência cresce e culmina com a greve geral de maio de 1968, para uma transformação das condições de trabalho e o pelo direito de os trabalhadores se recusarem a "perder sua vida para ganhála”. Entretanto, serão necessários mais de dez anos e a chegada da esquerda ao poder para que $o s$ "novos direitos" dos trabalhadores sejam objeto das "leis Auroux" (1982), que inscrevem esses direitos no Código do Trabalho. Os sindicatos entram na empresa, com a criação de seções sindicais internas para a defesa dos direitos dos trabalhadores. Os Comités d'hygiène, de sécurité et de conditions de travail (CHSCT) ${ }^{3}$ se tornam uma instituição representativa dos trabalhadores, exercendo um real contrapoder no seio da empresa. Enfim, um direito de expressão dos trabalhadores sobre as condições de trabalho é instituído, abrindo o caminho ao direito de se retirar de situações de trabalho perigosas.

\section{A “DESORGANIZAÇÃO” DO TRABALHO}

Desde os anos 1970, em reação ao crescimento dos contrapoderes, especialmente desde 1968, o patronato coloca uma exigência absoluta: a flexibilidade dos empregos, acarretando uma precarização estrutural, bem como uma forte intensificação do trabalho. Por outro lado, intensifica-se o movimento de globalização da produção rumo à Ásia e à América Latina, mas também aos países da Europa do Leste, iniciado nos anos 1960. As estratégias de desorganização do trabalho desenvolvidas pelos dirigentes das empresas multinacionais, apoiadas pelo poder político, se opõem ao exercício dos direitos de trabalhadores conquistados em lutas anteriores.

\section{Precarização do trabalho}

A legalização do trabalho temporário, em

${ }^{3}$ Comitês de Higiene, Segurança e Condições de Trabalho.
1972, e da terceirização, em 1975, põe em perigo mais de um século de proibição de intermediação de mão de obra, mesmo se formalmente essa proibição permaneça inscrita no Código do Trabalho, e que um inspetor do trabalho possa provar que o motivo exclusivo de uma prestação de serviço entre duas empresas dizia respeito estritamente à locação de mão de obra, e não à realização de uma tarefa específica.

O termo "trabalhadores exteriores", que designa os terceirizados, aparece então na linguagem regulamentar: um decreto de novembro de 1977 (revisado em 1992) tem por objeto as "prescrições de segurança concernentes à intervenção de 'empresas exteriores' (terceiras) no local de uma empresa tomadora", como se se tratasse de uma nova categoria de empresas e de assalariados. Desde 1978, o estudo de um advogado especialista em direito do trabalho, Bernard Rettenbach, publicado pelo Ministério da Justiça, adverte os poderes públicos contra a fragilização, pela terceirização, das garantias associadas ao contrato de trabalho, quando a empresa pode "modificar livremente o quadro em que se exercem os direitos e as obrigações mútuas" (Rettenbach, 1978).

Quinze anos mais tarde, Alain Supiot observa a existência, doravante, de uma "fratura interna ao direito do trabalho entre, por um lado, os trabalhadores que desfrutam plenamente dos direitos da pessoa, garantidos pelo contrato de trabalho "típico" e, por outro lado, aqueles que, por causa de um contrato atípico, ficam sujeitos ao "trabalho como mercadoria" (Supiot A., 1994). No discurso político e no das ciências sociais, entretanto, a precariedade aparece como um "flagelo social" em si, espécie de atributo pessoal de populações supostamente vulneráveis ou nãoempregáveis... Ora, os dois fenômenos - flexibilidade e precariedade - são indissoluvelmente ligados. "Nova forma de dominação no trabalho", a modernização pela flexibilidade quebra, de modo encoberto, as frágeis conquistas das décadas precedentes (As novas formas de dominação no trabalho, 1996). É o que mostra a obra 
coletiva Precarização, trabalho, saúde (Appay; Thébaud-Mony, 1997).

A terceirização se tornou a principal ferramenta de gestão do trabalho, em primeiro lugar, nas funções anexas à produção, tal como a vigilância, a limpeza e a restauração industrial. Muito rapidamente, esse modo de gestão da mão de obra se generalizou, tornando-se, em numerosos setores de atividade, a principal "variável de ajuste" às circunstâncias da conjuntura (de acordo com o vocabulário dos economistas). No setor automobilístico ou aeroespacial, os construtores apenas mantêm internamente a montagem dos veículos ou dos aviões. A fabricação das peças é realizada por cadeias de terceirizados, postos regularmente em concorrência por licitações, permitindo ao dirigente impor uma lógica permanente do menor preço. A construção dos navios nos canteiros navais ocasiona mercados de terceirização, pondo em concorrência as empresas europeias de fornecimento de mão de obra ditas de "serviços", o que vai reforçar a adoção, em 15 de novembro de 2006, da diretriz Bolkestein ${ }^{4}$ sobre a liberalização dos serviços. Nos canteiros de obras da construção civil, as grandes marcas do setor - Bouygues, Spie, Fougerolles escondem redes de pequenas e médias empresas, cada vez mais provenientes de países do sul ou do leste da Europa, onde os salários são menores que os da França e as condições de trabalho muito degradadas. Estas empresas operam com cascatas de subcontratações e recorrem aos trabalhadores intermitentes, ao trabalho independente e ao trabalho não-declarado (frequentemente realizado por trabalhadores ditos "sem documentos”). Nos locais das indústrias petroquímicas, químicas, metalúrgicas e nucleares, a manutenção é feita por empresas ditas "prestadoras".

Essa precarização resulta de escolhas estratégicas que visam, segundo os dirigentes industriais, à "modernização da organização do tra-

${ }^{4} \mathrm{O}$ texto da Diretiva Bolkestein previa a total supressão da regulamentacões nacionais sobre os servicos, além do fim da autonomia de cada Estado para definir a natureza e o financiamento dos serviços públicos. Recebeu o nome do Comissário da União Europeia para Mercado Interno, Frits Bolkestein. balho", o que corresponde, na realidade, a uma desorganização do trabalho e das relações salariais, apoiada pelos poderes públicos.

\section{Intensificação do trabalho e deslocalização}

Essas transformações do trabalho resultam, em primeiro lugar, das estratégias das grandes empresas, para as quais o recurso à terceirização de atividades - como a manutenção, a limpeza ou a gestão dos resíduos - permite transferir a gestão dos riscos (econômicos e sanitários) para os assalariados de empresas terceirizadas, no âmbito de uma situação de concorrência entre essas empresas, e, assim, dos próprios assalariados na hora dos procedimentos de licitação. O contrato comercial não é submetido ao direito do trabalho, mas às exigências do "cliente" - ou seja, a empresa contratante -, que não são negociáveis. Assim, desaparece qualquer espaço de discussão e de negociação das condições de trabalho entre aquele que prescreve o trabalho, a empresa contratante, e aqueles que o executam, os trabalhadores terceirizados, submetidos não mais a uma obrigação de trabalho, mas a uma obrigação de resultados. No caso da limpeza industrial, na indústria química ou aeronáutica, por exemplo, a limpeza requerida das instalações ou dos aviões é definida por meio das normas de qualidade. Os assalariados devem satisfazer essas normas, quaisquer que sejam as condições de realização e os meios dados para fazê-lo. Cada assalariado é considerado individualmente responsável pelo respeito às normas e aos procedimentos. A ausência habitual de sindicatos nas empresas prestadoras representa um obstáculo à construção de margens de negociação, e isso ainda mais porque, frequentemente, no momento da assinatura do contrato, os "clientes" exigem a ausência de sindicalistas aptos a construir formas de resistência coletiva. Essas práticas são, muitas vezes, completadas por formas mais ou menos explícitas de chantagem no emprego, pela ameaça onipresente da deslocalização, conforme testemunho no quadro a seguir. 
"Crise" e deslocalização: o exemplo de Airbus-industries

Em outubro de 2006, explode a crise em Airbus-Industries. ${ }^{5} \mathrm{O}$ avião A380 não sairá a tempo das oficinas para honrar o cronograma planejado. Ora, essa "crise" é muito reveladora das escolhas atuais de organização do trabalho, que consiste, da parte das grandes empresas contratantes, em delegar a alguém mais fraco e a menor custo, o cuidado de resolver todos os enigmas da produção, no tempo certo, de um avião cujo projeto provém da megalomania industrial. Pouco importa esses enigmas, e o trabalho necessário para resolvê-los; os terceirizados deviam respeitar seus compromissos: tudo é culpa deles se os atrasos se acumularam! As consequências da crise não atingem os salários dos dirigentes de AirbusIndustries e os dividendos dos acionistas, mas se traduzem pela demissão de milhares de trabalhadores sem estatuto e, para alguns, sem esperança de reencontrar um emprego nos meses que seguem. Cerca de 32000 empregos da região ficam ameaçados. Os assalariados diretos da Airbus-Industries se isolam pensando que sua vez poderia chegar se a diretoria não encontrasse os meios de enfrentar as dificuldades. Durante esse tempo, para o "reordenamento" da organização da construção final do avião, os dirigentes da AirbusIndustries preveem reduzir em $20 \%$ os custos de produção do novo avião. Isto quer dizer, com todas as letras, uma intensificação do trabalho para todos os assalariados e terceirizados que terão a "sorte" de conservar seu emprego. Evidentemente, nesse contexto, não pode se cogitar uma melhoria das condições de trabalho. A hora é de urgência produtiva! Aliás, mesmo assim, medidas mais enérgicas ainda se impõem. No mercado dos fabricantes de peças, os trabalhadores franceses são mais caros que os turcos. Fabricantes de peças tomam então a decisão de "deslocalizar" certos segmentos da produção para a Turquia! [...] É possível até levantar a hipótese de que os turcos serão caros demais em alguns meses, se comparados com o que oferecem os chineses. O mundo, decididamente, é uma aldeia para os impérios industriais que nos governam... Quanto aos acidentes de trabalho e doenças profissionais devidas à construção desse avião gigante, caso se produzam na França e que sejam declarados, não serão contabilizados na atividade aeronáutica, mas nos setores a que pertencem as empresas terceirizadas. Caso se produzam na Turquia ou na China, não serão recenseados em nenhum lugar. A Airbus-Industries poderá, assim, aparecer, com todas as certificações ISO do mundo, como uma das indústrias mais seguras do planeta! ((Thébaud-Mony, Annie, Travailler peut nuire gravement à votre santé, 2007)

A desorganização do trabalho passa também, como já evocamos, por políticas públicas em apoio às estratégias industriais. Tal foi o caso das leis sobre o trabalho temporário e a terceirização dos anos 1970, que construíram os apoios legislativos necessários às estratégias de flexibilidade e precarização do trabalho. Em 1986, uma regra protetora do emprego desaparece, por sua vez. Trata-se da supressão da auto-

\footnotetext{
${ }^{5}$ Le Monde-économie, 17 de outubro de 2006.
}

rização prévia pelo inspetor do trabalho de uma decisão de demissão. Antes de 1986, um empregador que quisesse demitir um assalariado sob contrato de duração indeterminada devia apresentar a prova de que estava com dificuldades econômicas. $\mathrm{O}$ inspetor do trabalho constatava a situação e concedia - ou não - a autorização para a demissão. A supressão dessa autorização - sob a alegação de "simplificação administrativa” - abriu o caminho para reduções massivas de efetivos, ao tempo em que acelerava o processo de deslocalização das empresas. 


\section{AS CONSEQUÊNCIAS DESSAS ESCOLHAS SOBRE O EMPREGO E A SAÚDE DOS TRABALHADORES}

Desde o início dos anos 1980, o desemprego é estrutural. Na França, a discussão tem por objeto não o fenômeno, por si próprio incontestável, mas a sua amplitude. ${ }^{6}$ A categoria oficial dos que "procuram de emprego" é definida assim: as pessoas em busca de emprego de tempo integral com contrato de trabalho de duração indeterminada. Seu número, em 2010, se eleva a 2.700.000. Quando se acrescentam as outras categorias de pessoas "sem emprego" - pessoas procurando um contrato de duração determinada ou um emprego em tempo parcial, pessoas excluídas do seguro desemprego por vencimento de prazo, ou que não manifestaram uma vontade suficiente de procura de emprego, e idosos de mais de 55 anos -, o desemprego atinge cerca de seis milhões de pessoas, para uma população ativa assalariada de 18 milhões de pessoas.

Numerosos trabalhos de pesquisa, na Europa (Appay, Thébaud-Mony, 1997; ThébaudMony, 2000; BTS/SALTSA, 2000; Seillan; Morvan, 2005; Hery, 2009), no Canadá (Lippel, 2004), na Austrália (Quinlan; Mayhew, 1999, 2001) e no Brasil (Druck; Franco, 2009) relatam o impacto do recurso à terceirização e ao trabalho temporário sobre a saúde dos trabalhadores e sobre a efetividade dos dispositivos de prevenção e de reparação dos acidentes do trabalho e doenças profissionais. Os pesquisadores apontam quatro pontos-chave da articulação entre o que o $\mathrm{M}$. Quinlan \& C. Mayhew designam como a "(des) organização" do trabalho e da saúde no trabalho.

Em primeiro lugar, eles sublinham o agravamento constante, há 20 anos, das desigualdades na repartição dos riscos e das condições de trabalho entre trabalhadores estatutários de empresas contratantes e trabalhadores exteriores e (ou) temporários, que dependem de estatutos extremamente diversos e são submetidos a formas

${ }^{6} \mathrm{http}: / /$ www.chomiste-land.com/chiffrechomage.htm mais ou menos acentuadas de precariedade. $\mathrm{Na}$ França, segundo os resultados da enquete SUMER 2003, a parte mais importante é a acumulação das exposições aos riscos profissionais, dos quais, em especial, a exposição aos agentes cancerígenos concentra-se nas operações de conservação e manutenção - no mais das vezes sistematicamente terceirizadas - e para os assalariados com contrato de curto prazo, intermitentes e até mesmo os estagiários (Guignon; Sandret; 2005).

Em segundo lugar, essas transformações da organização do trabalho pelo recurso à terceirização colocam um obstáculo à implementação dos dispositivos regulamentares e legislativos de prevenção e de reparação dos agravos à saúde ligados ao trabalho. Qualquer que seja o país, os pesquisadores insistem no fato de que esses dispositivos não evoluíram em função das transformações observadas. Eles permanecem fundados sobre o modelo do contrato de trabalho de longa duração entre um empregador e um assalariado. Eles não levam em conta nenhuma das situações que acarretam para o trabalhador uma obrigação de trabalho em relação a vários empregadores dos quais um só é seu empregador no sentido tradicional do contrato de trabalho. Isso torna, muitas vezes, inoperantes os direitos que este, supostamente, garante. M. Quinlan, na Austrália (1999, 2001), Katherine Lippell, no Canadá (2004), mostram a "erosão" dos direitos ao reconhecimento do acidente do trabalho e da doença profissional, associada a essa evolução da organização do trabalho.

Em terceiro lugar, e em consequência do ponto precedente, todos os autores sublinham a invisibilidade dos agravos ligados ao trabalho em especial os cânceres - pela fragilização dos dispositivos de vigilância, de acompanhamento da saúde dos trabalhadores submetidos a essas formas de emprego e de identificação dos agravos ligados ao trabalho (Thébaud-Mony; 2008).

Em quarto lugar, os autores insistem no questionamento radical dos direitos à representação sindical e à expressão sobre as condições de trabalho (Quinlan; 1999; Nichols; Walter, 
2009). A distância não cessa de aumentar entre os direitos dos trabalhadores protegidos, que usufruem de garantias salariais e de formas de representação institucionalizada, e os dos trabalhadores que vivem no âmbito da cadeia de terceirização, uma relação individualizada com o emprego e o trabalho.

\section{CÂNCERES PROFISSIONAIS: romper a invisibilidade}

Entre os riscos que ficaram especialmente invisíveis, figuram os cânceres profissionais. Após ter evocado as razões de sua invisibilidade, esse último ponto relata uma démarche de pesquisaação, que coloca em evidência a importante transferência de risco para as categorias precarizadas do assalariado, ao tempo em que oferece as bases de novas formas de resistência operária para a saúde, a vida, a dignidade.

\section{Uma invisibilidade socialmente construída}

Na França, nos anos 1990, um movimento social sem precedente contra o amianto obteve a proibição total dessa fibra mortal e revelou a catástrofe sanitária que ela provocou: mais de 100 mil mortes na França e a previsão de cerca de 500 mil mortes na União Europeia até 2025. $\mathrm{O}$ fato que elas sejam colocadas em evidência a partir de 1997 não pode fazer esquecer as décadas durante as quais os cânceres foram ignorados e as razões dessa negação (Thébaud-Mony, 2007). Mas o caso do amianto não deve, por sua vez, esconder os outros riscos de câncer profissional. É por isso que importa questionar os dados oficiais sobre o câncer e sua interpretação e descobrir sobre os conhecimentos em que está embasada a visibilidade ou invisibilidade dos cânceres profissionais.

Uma das características principais do câncer é a de ser uma enfermidade com distribuição desigual. De acordo com a revisão bibliográ- fica sobre as desigualdades sociais face ao câncer, realizada pelo Centre International de Recherche sur le Cancer (CIRC) ${ }^{7}$ em todos os países que dispõem de dados estatísticos de mortalidade por categorias socioprofissionais, a mortalidade por câncer, em especial a mortalidade precoce (antes de 65 anos) é mais elevada entre os operários do que entre os quadros e profissões intelectuais (Kogevinas et al, 1997). Na mesma obra, os autores estimam que a terça parte do número mais elevado de cânceres observado nas categorias sociais desfavorecidas, se comparadas aos grupos sociais mais favorecidos, seria ligada à exposição profissional a substâncias cancerígenas industriais.

No entanto, é importante levar em conta as características particulares do câncer, que não responde ao modelo biológico clássico "uma causa = um efeito”. O câncer é um processo longo, que dura frequentemente várias décadas da vida de um indivíduo. Esse processo se realiza em várias etapas e se desenvolve em interação entre as exposições simultâneas e sucessivas do indivíduo a agentes cancerígenos (em seu meio de trabalho e de vida), e sua inscrição no seu desenvolvimento biológico e vital. Sabe-se que, face ao acometimento celular por um agente cancerígeno, o organismo reage por estratégias de reparação que podem ser globais, deixando o campo aberto a uma "reparação" efetiva sem sequelas, ou pelo contrário, parciais, permitindo então a sobrevivência de células cancerígenas que encontrarão, na interação constante entre o indivíduo e seu "ambiente" (pessoal e profissional), as condições de desenvolvimento de tumores cancerígenos. Os trabalhos sobre os efeitos de sinergia de exposições acumuladas ao amianto e ao tabaco mostraram que o risco de ocorrência do câncer é multiplicado quando o indivíduo é exposto a ambas as substâncias. É preciso igualmente insistir sobre o fato de que não há "assinatura" do câncer que permita "escolher", para um indivíduo acometido de câncer, entre ${ }^{7}$ Centro Internacional de Pesquisa sobre o Câncer. 
diferentes causas. A história da exposição a agentes cancerígenos de um paciente acometido de câncer pode ser reconstituída, mas ela não permite identificar a "causa" desse câncer, sendo mais provável que cada um dos diferentes agentes cancerígenos aos quais o paciente foi exposto possa ter desempenhado um papel no processo, gerando e permitindo o desenvolvimento desse câncer.

Além desses dados importantes, concernentes às dificuldades de identificação dos cânceres ligados ao trabalho, sua invisibilidade se encontra em três outras fontes: a ignorância tóxica, a invisibilidade física e a invisibilidade social.

A ignorância tóxica se deve, em primeiro lugar, a um desconhecimento muito grande da toxicidade das substâncias químicas presentes na atividade de trabalho. A produção mundial de substâncias químicas passou de um milhão de toneladas em 1930 a mais de quatrocentos milhões em nossos dias. Porém, de acordo com a agência americana de proteção do meio ambiente (EPA), somente $7 \%$ das substâncias introduzidas na produção industrial foram objeto de uma pesquisa de toxicidade cujos dados são disponíveis. A essas substâncias é preciso acrescentar as poluições provenientes do próprio processo de produção, sob forma de poeiras, fumaças, gases, radiações, cuja toxicidade está longe de ter sido sistematicamente estudada.

Ora, conforme os princípios de inscrição de uma substância cancerígena na lista oficial de agentes cancerígenos estabelecida pelo CIRC, uma substância será considerada cancerígena em função de estudos experimentais (in vivo, in vitro) e de estudos epidemiológicos que sejam objeto de um consenso no âmbito de grupos de trabalho reunidos pelo CIRC. Esse consenso se dá em torno a um conceito-chave, aquele de uma "evidência suficiente da cancerogenicidade entre os humanos" (WHO/IARC, 2006). Tal evidência depende da realização de estudos com resultados convergentes. Ora, a toxicologia industrial é uma disciplina quase inexistente em numerosos países, entre os quais a França, o que limita grandemente a possibilidade de mobilizar os estudos de toxicidade indispensáveis. Quanto à epidemiologia, ela conhece limites importantes, em especial em relação à precarização do trabalho. Isso pode ser ilustrado pela enquete internacional sobre os cânceres devidos à exposição às radiações ionizantes entre os trabalhadores da indústria nuclear (Cardis, 2005), enquete que, por razões metodológicas, excluiu os trabalhadores terceirizados que, no entanto, recebem mais de $80 \%$ da exposição às radiações ionizantes nos sítios nucleares. Essa exclusão da população mais exposta - mais precarizada - evidencia o ângulo cego da démarche epidemiológica, visto que a população recenseada não leva em conta a realidade da desigual repartição dos riscos.

A invisibilidade física dos agentes cancerígenos reside no fato de que escapam, como risco mortal, à percepção imediata dos trabalhadores: as poeiras, as fumaças, os gases, as radiações, muitas vezes, não têm nenhum efeito perceptível, a não ser sob forma de irritação, de incômodos e outros sintomas considerados como benignos. A medida do perigo escapa às pessoas expostas, já que depende de ferramentas técnicas geralmente em mãos de organismos especializados. As consequências só serão perceptíveis anos ou décadas mais tarde. Essa invisibilidade física é reforçada por um acesso frequentemente difícil à informação sobre os agentes cancerígenos presentes no ambiente de trabalho, em especial quando se trata não de produtos rotulados, mas de agentes cancerígenos que provêm diretamente do processo de produção, como no caso das fumaças de combustão, dos subprodutos, dos contaminantes ou das fibras de amianto ou de sílica respiradas por ocasião dos canteiros de demolição, em especial no setor da construção civil e em obras públicas. Essa invisibilidade dos agentes cancerígenos é reforçada pelo fato de existir um tempo de latência muito longo entre o momento da exposição no trabalho e o aparecimento do câncer. Isso pode levar a que a doença se manifeste quando o trabalhador se aposentar.

Enfim, a invisibilidade social é aquela que 
resulta da não-aplicação de regras vigentes, concernentes à obrigação de os empregadores declararem os produtos e processos que ocasionam doença profissional e do caráter restritivo da reparação dos cânceres profissionais na França. Menos de mil e oitocentos casos são reconhecidos a cada ano, para várias dezenas de milhares de ocorrências, e até mais. Essa invisibilidade social é também o resultado da falta de registro adequado da ocupação do trabalhador nas diversas fichas e registros médicos.

É com o auxílio desses diferentes tipos de dados que o Groupement d'Intérêt Scientifique sur les Cancers d'Origine Professionnelle (GISCOP93) ${ }^{8}$ da Universidade Paris 13 reconstituiu os percursos profissionais de pacientes acometidos de câncer. Considerando o câncer como um "eventosentinela", essa démarche permite romper a invisibilidade das exposições profissionais aos agentes cancerígenos e evidenciar não somente o déficit de indenização das vítimas de cânceres profissionais, mas também as necessidades de prevenção das exposições nos locais de trabalho.

\section{A doença: evento-sentinela}

Desde março de 2002, uma enquete permanente é realizada junto aos pacientes de três hospitais da Seine-Saint-Denis (Centro Hospitalar Universitário Avicennes, Hospital de Monfermeil, Hospital Robert Ballanger em Aulnay-sous-Bois). O questionário contempla os novos pacientes acometidos de câncer, que residem em Seine-Saint-Denis, para localizações ou patologias suscetíveis de estar em relação com uma ou várias exposições profissionais (cânceres respiratórios, urinários, hematológicos). Para cada um desses pacientes, em vez de olhar somente um ramo de atividade, é feita uma reconstituição aprofundada de seu percurso profissional no decorrer de uma entrevista, seja no domicílio, seja no hospital. Cada um dos per-

${ }^{8}$ Grupamento de Interesse Científico sobre os Cânceres de Origem Profissional cursos é, em seguida, periciado e dá lugar, no âmbito de uma discussão coletiva dos experts, à realização de um debate sobre as características das exposições, seguido da decisão a tomar em relação à possibilidade de uma declaração como doença profissional. Quando essa doença é considerada como possível pelos experts, a equipe de pesquisa remete ao médico do paciente essa informação, permitindo estabelecer um certificado inicial de doença profissional.

Entre $1^{\circ}$ de março de 2002 e 25 de maio de 2010, no conjunto de 985 pacientes que fizeram reconstituição de seu percurso profissional (metade com menos de 65 anos), 827 foram expostos a agentes cancerígenos (ou seja, 84\%). Trata-se de uma exposição múltipla (três agentes cancerígenos ou mais para $55 \%$ dos pacientes), em níveis elevados e de longa duração (68\% dos pacientes cumulam mais de 20 anos de atividade de trabalho expostos a um ou vários agentes cancerígenos).

Descrever percursos profissionais que ocorreram em média nos 30 a 60 últimos anos é observar como esses percursos se inscrevem em períodos sucessivos, marcados pelas transformações do trabalho, evocadas anteriormente.

A análise dos percursos profissionais dos pacientes entrevistados permitiu estabelecer uma tipologia desses percursos em quatro tipos (Thébaud-Mony et al, 2003). Para um terço dos pacientes entrevistados no decorrer dos dois primeiros anos de enquete, os percursos apresentam uma continuidade da atividade de trabalho para pessoas que trabalharam quase exclusivamente na mesma empresa, ou de modo estável em dois empregos diferentes. Para todos os outros, os percursos profissionais testemunham descontinuidades no emprego e na atividade. Menos de um quarto desses últimos se inscreve em um processo de mobilidade ascendente. Os três quartos restantes tiveram percursos descontínuos sem ganho de qualificação, mas também, por vezes, entrecortados de períodos de desemprego e de reinserção em empregos menos qualificados que os precedentes. Outra 
característica desses percursos é, para a maior parte dos pacientes, sua inserção em funções anexas à produção - conservação, limpeza, manutenção, demolição -, as quais não são, de modo algum, obsoletas hoje e que evoluem relativamente pouco do ponto de vista técnico, tornando altamente provável a persistência, nessas atividades, de exposição a substâncias cancerígenas. ${ }^{9} \mathrm{~A}$ diferenciação dos percursos profissionais bem como a diversidade dos "ofícios", das atividades e dos lugares de trabalho condicionam igualmente uma diversificação das histórias de exposição aos agentes cancerígenos profissionais, figurando na lista estabelecida pelos experts do GISCOP.

Essas histórias de exposição aos agentes cancerígenos testemunham, em primeiro lugar, a exposição múltipla a agentes cancerígenos profissionais, sabendo-se que, globalmente, $84 \%$ dos pacientes têm sofrido exposições a esses agentes e $55 \%$ dos pacientes foram expostos a pelo menos três destsas substâncias e procedimentos cancerígenos. A exposição é forte ou média para 90\% dos pacientes, com uma duração superior a 20 anos em 70\% dos casos. Os relatos dos pacientes testemunham a ausência total de proteção coletiva ou individual. Os setores de atividade mais representados são os da construção, seguidos pelos trabalhos dos metais e do conserto de automóveis, bem como a limpeza e outros setores industriais. Enfim, se o amianto permanece fortemente presente, em especial na construção, na metalurgia, e na reparação dos carros, numerosos outros agentes cancerígenos são igualmente identificados nos percursos profissionais dos pacientes, em especial os hidrocarbonetos policíclicos aromáticos, a sílica, as fumaças de soldagem, os solventes, o chumbo, os cromatos, as fumaças de gasolina e diesel, o benzeno, as radiações ionizantes, etc..

"Cânceres profissionais: uma chaga social muitas vezes ignorada” (Mangeot, 2007). Foi

${ }^{9} \mathrm{O}$ amianto fornece um bom exemplo da persistência das exposições profissionais aos agentes cancerígenos. Há aproximadamente $75 \mathrm{~kg}$ de amianto por habitante na França do qual uma grande parte nos edifícios. Qualquer operação de renovação começa pela demolição. Em numerosos casos, o amianto está presente nos tetos falsos, nas bainhas técnicas, nos isolamentos térmicos de tubulações, etc. assim que a brochura editada pelo Instituto Europeu pela Pesquisa, a Formação e a Saúde- segurança qualifica a situação atual em matéria de conhecimento e de prevenção dos cânceres profissionais. Os resultados da enquete realizada em Seine-Saint-Denis contribuem para quebrar o silêncio em torno dos cânceres profissionais. Profissionais da saúde no trabalho, inspetores do trabalho e sindicalistas se mobilizam para a prevenção, apoiados por pesquisadores como aqueles do GISCOP93 e advogados que, cada vez mais, se engajam ao lado dos coletivos para defender, diante dos tribunais da justiça civil e penal, o direito dos trabalhadores a uma atividade efetivamente protegida dos riscos imediatos ou com efeitos retardados.

\section{CONCLUSÃO}

Novas redes de resistência à evolução de doenças ocupacionais analisadas neste artigo se desenvolvem. Essas redes se constituem numa base cidadã, aliando pesquisadores, sindicalistas, juristas, políticos e jornalistas. Contra uma evolução que prescinde das fronteiras, essas redes são imediatamente internacionais, como mostra a luta contra o amianto. ${ }^{10}$ A uma globalização econômica deve responder uma globalização dos contrapoderes, essa "globalização por baixo", tal como é definida por Fernanda Giannasi, ${ }^{11}$ figura emblemática, no Brasil, da luta pela saúde no trabalho:

A globalização por baixo questiona o paradigma segundo o qual o progresso seria indissociável do crescimento econômico. Ela rompe igualmente com uma concepção da política fechada em organizações hierárquicas e piramidais que não têm, em realidade, outro objetivo senão aquele de acumular o poder e exercê-lo em nome da base, sem participação efetiva dela. É o caso da maioria dos partidos políticos e dos sindicatos. Numa reação crítica a este modelo piramidal autoritário, numerosas redes de contrapoderes nasceram (para a proibição do amianto, contra os produtos orgânicos persistentes, contra a produção e o uso

${ }^{10}$ Ver os sites: http://ibasecretariat.org/, www.abrea.com.br/ www.ban-amiantos-france.com/

${ }^{11}$ Texto disponível em: www.abrea.com.br 
do mercúrio, pelo reconhecimento dos direitos das vítimas de silicose, de TMS, etc.). Numa perspectiva de globalização contra-hegemônica, esses movimentos se constituem de maneira horizontal, como uma rede de inúmeros fios, rede que pode se desenvolver infinitamente por todos os lados, sem que qualquer, sem que nenhum de seus nós possa ser considerado como sendo principal ou central, sem representante dos outros, sem nenhum entrave ao fluxo das informações e numa socialização efetiva das decisões a tomar. [...] Os contrapoderes assim constituídos desenham a configuração de um movimento político novo, orientado para a transformação social, a busca de uma sociedade mais justa, igualitária e que respeite o direito à vida, à saúde.

O direito ao respeito da integridade da pessoa, o direito à saúde e o direito à dignidade não dependem da negociação salarial, mas de princípios que fundam a cidadania. O princípio de justiça passa em primeiro lugar pela igualdade diante da lei.

No campo da prevenção dos riscos profissionais na França, o recurso generalizado à terceirização questiona radicalmente esse princípio de igualdade diante da lei. Na França, a constituição de um assalariado, prisioneiro de relações "cliente-fornecedor", que está constantemente em uma situação em que o direito pode ser violado, frequentemente precário, questiona não somente uma parte das regras do Código do Trabalho referentes às condições de trabalho como também a instituição representativa e a referência na matéria, a saber, os CHSCT (Comité d'Hygiène, de Sécurité, et des Condittions de Travail). As instituições - medicina do trabalho, inspeção do trabalho - encontram dificuldades muito grandes no exercício de suas missões.

Assim, o que está em causa não são tanto as regras do direito do trabalho nelas mesmas, mas sua efetividade para os trabalhadores. Tratase de "fazer ressurgir o trabalhador como sujeito de direito", segundo os termos de A. Supiot (1994) e de lhe dar os meios, individual e coletivamente, com a ajuda de experts exteriores independentes, de tomar parte ativa no dispositivo de conhecimento e de prevenção dos riscos profissionais. A construção de uma responsabilidade jurídica ple- na e inteira das empresas contratantes e de diretores das grandes empresas é indispensável. Ora, até o presente momento, na França, os crimes, delitos e infrações dos empregadores e dirigentes contra os trabalhadores, de referência ao direito do trabalho e ao direito penal, gozam, na sua imensa maioria, de uma total impunidade.

Essa impunidade é atualmente questionada no âmbito de um processo emblemático que acontece, não na França, mas na Itália, em Turim. Os mais altos dirigentes, o suíço (Stephan Schmidheiny) e o belga (Louis Cartier de Marchienne), da multinacional Eternit são julgados pelo tribunal penal, por terem provocado, deliberadamente, um desastre sanitário na Itália, em especial em Casale Monferrato, o que resultou em milhares de vítimas do amianto. ${ }^{12}$ A decisão do tribunal é esperada para o mês de setembro próximo. Essa decisão poderia fazer jurisprudência no nível internacional, não diretamente, mas mediante novas instituições judiciárias internacionais. Um tribunal penal internacional foi criado para julgar os crimes contra a humanidade. Por que não a criação de um tribunal penal internacional do trabalho e do meio ambiente, diante do qual seriam levados à justiça aqueles que, cientemente, transformam o trabalho em um lugar de violência e de morte? Tal iniciativa política está em debate nas redes internacionais.

A saúde dos trabalhadores não é campo reservado de alguns especialistas provenientes dos meios científicos ou médicos, sindicais ou associativos. Todos os saberes, todas as experiências são necessárias para impor o respeito aos direitos fundamentais dos trabalhadores contra a dominação econômica. Ela supõe a mobilização de todos aqueles - homens e mulheres, trabalhadores e pessoas sem emprego, pesquisadores, intelectuais, juristas e personalidades políticas - que consideram inaceitável o fato de perder sua vida para ganhá-la.

(Recebido para publicação em 03 janeiro de 2011) (Aceito em 18 de abril de 2011)

\footnotetext{
${ }^{12}$ http://amiantosinthedock.ning.com
} 


\section{REFERÊNCIAS}

APPAY, B.; THÉBAUD-MONY A. (Dir.) Précarisation sociale, travail et santé. Paris: CNRS, IRESCO/Inserm, 1997

BTS/SALTSA. Le travail sans limite? In: CONFERENCE EUROPEENNE. Bruxelles: sept. 2000.

CITOYENS résistants d'hier et d'aujourd'hui. Le programme du Conseil National de la Résistance de mars 1944: commen il a été écrit et mis en oeuvre, et comment Sarkozy accélère sa démolition. Paris: La Découverte, 2010 (Cahiers libres).

DRUCK, G.; FRANCO, T. La sous-traitance au Brésil: un phénomène à la fois ancien et nouveau. PISTES, v.11, n.1 mai, 2009. Disponible en: http://www.pistes.uqam.ca

GUIGNON, N.; SANDRET, N. Les expositions aux produits cancérogènes. Premières synthèse, premières informations, n. 28-1, juil., 2005

HÉRY, M. (Dir.) La sous-traitance interne. Paris: EDP Siences/ INRS, 2009 (Coll. avis d'experts).

KOGEVINAS, K.; PEARCE N.; SUSSER, M.; BOFFETA, P. (Éd.) Social inequalities and cancer. Lyon: IARC, 1997. (Scientific publications,138)

LES NOUVELLES formes de domination dans le travail. Actes de la Recherche en Sciences Sociales, Paris, n.114, 115 sept., dec. 1996.

LIPPEL, K. Le travail atypique et la législation en matière de santé et sécurité du travail 201. Développements récents en santé et sécurité du travail Cowansville: Editions Yvon Blais,, 2004. p.307-383

MANGEOT M.A. Les cancers professionnels: une plaie sociale trop souvent ignorée. Bruxelles: ETUI-REHS, 2007.

NICHOLS, T.; WALTER, D. (Ed.) Workplace health and safety. In: INTERNATIONAL PERSPECTIVES ON WORKER REPRESENTATION. Basingstoke: Palgrave Macmillan, 2009, v.XV + 232 p.

QUINLAN M.; MAYHEW C.; BOHLE P. The global expansion of precarious employment, work disorganisation, and consequences for occupational health. Internationa Journal of Health Services: a review of recent research. Paris, v.31, n.2, 3, 2001.
Precarious employment and worker's compensation. International Journal of Law and Psychiatry, New York, Elsevier, v.22, p.491-520, 1999.

RETTENBACH, B. Droit du travail et restructurations productives. Les nouveaux contrats de travail. Paris: La Documentation francaise, 1978.

REVUE D'HISTOIRE DES ACCIDENTS DU TRAVAIL n.10, 11, 1981

SEILLAN, H.; MORVAN, J. Risques de la sous-traitance. 2.ed. Les Cahiers de Préventique, Bordeaux, n.4, 2005. (Editions préventique)

SUPIOTA. Critique du droit du travail. Paris: PUF, 1994.

THÉBAUD-MONY A. L'envers des sociétés industrielles. Approche comparative franco-brésilienne, Paris: L'Harmattan, 1990.

Nuclear servitude: subcontracting and health in the French civil nuclear industry (préface et traduction de l'ouvrage paru en 2000 aux éditions Inserm/EDK). Baywood: Inserm, 2000. (Sous presse)

. Travailler peut nuire gravement à votre santé. Soustraitance des risque mise en danger d'autrui, atteintes à la dignité, souffrance physique et morale, cancer sprofessionnels, Paris: La Découverte, 2007.

Lindustrie nucléaire: sous-traitance et servitude. Paris: Inserm /EDK, 2000. (Coll. questions en santé publique, Paris 11).

Ouvrages et direction d'ouvrages

Construire la visibilité des cancers professionnels. Une enquête permanente en Seine-Saint-Denis. La Revue Française des Affaires Sociales, Paris, IAE, n.2, 2008.

; BOUJASSON, L.; LEVY, M.; LEPETIT, C.; GOULAMALY, P.;CARTERON, H.; VINCENTI, M. Parcourstravail et cancers professionnels. Recherche-action en Seine Saint Denis (France). PISTES: perspectives interdisciplinaires sur la santé et le travail, Montreal, Université du Québec, v.1, n.5, mai, 2003.

WHO/IARC. Iarc monographs on the evaluation of carcinogenic risks to humans. Preamble. Lyon: 2006. 


\section{PRECARIZATION OF LABOR AND RESISTANCES TO (RE)GAIN WORKERS' RIGHTS IN FRANCE}

\author{
Annie Thebaud-Mony
}

This paper initially presents some major historical stages of the conquest of workers'rights in France, emphasizing what led to a real official recognition of the rights in the fight to improve working conditions. During the seventies, when "flexibility" became the watchword of corporate restructuring, two laws questioning the banning of intermediation of labor and establishing a structural process of precarization of labor and employment, that changed not only the workers' economic security as the set of rights associated with the employment contract. This process unravels, in great part, the right to health of workers in the workplace, such as professional cancers, as reveals research a permanent research made in a parisian region, with patients suffering from cancer. New networks of resistance, most often internationally established and constituted on a citizenship basis organize themselves, however, about the health challenges, as addressed in the conclusion.

Keywords: precariousness, professional cancers, rights, resistances, France.

\section{LA PRÉCARISATION SOCIALE DU TRAVAIL ET LES RÉSISTANCES POUR (RE) CONQUÉRIR LES DROITS DES TRAVAILLEURS EN FRANCE}

\author{
Annie Thebaud-Mony
}

Cet article présente tout d'abord quelques grandes étapes historiques de la conquête des droits des travailleurs en France et met en évidence ce qui a conduit à une véritable reconnaissance officielle des droits dans la lutte pour l'amélioration des conditions de travail. Au cours des années 70, quand la "flexibilité" est devenue le mot d'ordre pour la restructuration des entreprises, deux lois remettent en question l'interdiction de l'intermédiation de la maind'œuvre qui a implanté un processus structurel de précarisation du travail et de l'emploi et qui a modifié non seulement la sécurité économique des salariés mais aussi l'ensemble des droits liés au contrat de travail. Ce processus démantèle en grande partie le droit à la santé des travailleurs sur leur lieu de travail, à l'exemple des cancers professionnels que révèle une enquête permanente faite en région parisienne auprès de patients atteints d'un cancer. Cependant de nouveaux réseaux de résistance, le plus souvent internationaux et constitués sur une base citoyenne, s'organisent face aux défis concernant la santé, comme démontré dans la conclusion.

MoTS-CLÉs: précarisation, cancers professionnels, droits, résistances, France. 